\title{
Clinical and Radiological Evaluation of Deviated Nasal Septum in Classifying and Surgical Management of the Deviated Septums.
}

\author{
Dr.Yugandhar Etigadda ${ }^{1}$, Dr.Juveria Majeed ${ }^{2}$, \\ ${ }^{1}$ RVS Institute Of Medical Sciences, RVS Nagar, Chittor, Andhra Pradesh. \\ ${ }^{2}$ Bhaskar Medical College,Yenkapally village, Moinabad,Telangana.
}

\begin{abstract}
:
Introduction:Nasal obstruction is one of the most common problems bringing patient to an ENT surgeon and deviated nasal septum is the most common cause of the problem. Yet there is no universally accepted classification of the septal deviation till now, for guiding the surgeon to do proper intervention in treating the problem. Various classifications were put forth by many surgeons, based on their clinical acumen and diagnostic imaging (like C.T. PNS), but none of them were accepted as a standard. In the present study, it has been attempted to classify the nasal septal deviation by clinical and Computerized Tomography findings of the patients. This study presents an analysis of the incidence of various types of the deviations and their management.

Aims And Objectives: 1.Clinical and radiological evaluation of deviated nasal septum to help in classifying and management.

2.In this study our aim is to accurately classify the type of deviated nasal septum and its further management.

Materials And Methods: During the period August 2013 to September 2014, 30 cases of nasal septal deviation diagnosed at our hospital (Govt. ENT Hospital, koti) were studied. Each patient's clinical details were taken down in a proforma (Data type).A total number of 100 cases have been examined endoscopically and CT scan findings were taken. 30 cases of various grades based on Mladina classification has been chosen for the present study. The endoscopic findings and CT scan findings have been compared and surgery planned accordingly.

Conclusions: A standard classification of nasal septal deviation should be developed and followed so that it can be included in evaluating the symptomatology and severity of the deviated nasal septum. Thorough evaluation of deviated nasal septum by endoscopy and comparison with CT scan of paranasal sinuses is an excellent protocol to achieve significantly successful surgical outcome. An attempt was made to study various classifications of deviated nasal septums in the literature and among those Mladina classification seemed to be more acceptable in evaluating deviated nasal septums.
\end{abstract}

Keywords:Deviated Nasal Septum, Mladinaclassification, Cottle's classification, Ballenger's , Negus Classification.

\section{Introduction}

Nasal Septal deviations are extremely common, but all of them affect nasal function. ${ }^{1}$ Many septal deviations are due to direct trauma ${ }^{2,3}$. Incidence of Septal deviation is not known, but at our institute, surgery for correction of septal deviation is done at a rate of $300-350$ per year and it is the second most common surgery performed after tonsillectomy. ${ }^{4}$ This indicates that incidence and prevalence is quite high in general population.

\section{Epidemiology:}

Nasal obstruction is a common complaint. In 1974, Vainio-Mattila found a $33 \%$ incidence of nasal airway obstruction among randomly chosen adults. ${ }^{5}$ Septal deviation was found to be the most frequently encountered structural malformation causing nasal obstruction. Clinically significant septal deviation was found in $26 \%$ of patients with nasal obstruction in this study.

Etiology:

Developmental septal deviation may occur. ${ }^{6}$ Patients in whom the septal cartilage has been damaged in the neonatal period and during birth can present with severe septal deviation in the absence of a history of nasal trauma. Microfractures sustained during late intrauterine life and during birth may cause weakness in the damaged side of the cartilage. ${ }^{7}$ The result is asymmetric bending of the cartilage toward the side of the injury, while the contralateral side achieves dominance over time. These conclusions are supported by evidence matching the direction of septal deviation with the presentation of the fetal head in the pelvis during delivery. Up to 20 percent of babies born are found to have 'squashed noses'. Majority spring back into place but about 12 per cent are left with a permanently deviated nasal septum which subsequently gives rise to nasal obstruction 
and snuffles. Excessive moulding of head distorts the posterior aspect of the septum which at this stage is cartilaginous and, if not immediately corrected, this eventually develops into deviated bony septum. ${ }^{8,9,10}$

In 1875, Sir Franzen Galton advocated the study of identical twins as a means of differentiating deformities caused by genetic and environmental factors. ${ }^{11}$ The distribution of the deviations within the twins suggested that anterior lesions are due to an external cause (trauma) where as the posterior lesions are due to genetic factors based on the study done by Grymer and Melson ${ }^{10}$ in 1989.

Gray $^{12}$ in 1972, proposed birth moulding theory according to which, abnormal intra uterine posture may result in compression forces acting on the nose and upper jaws. Displacement of the septum can result and the nose can be exposed to further torsion forces during parturition.

Septal deviation from traumatic impact can occur in childhood or adult life. Childhood trauma can cause severe nasal obstructive problems in adult life because any degree of septal deviation usually becomes more pronounced with time. The Fry principle also provides at least theoretical cause of deviated cartilaginous septum. The cartilaginous septum is composed of a sandwich of layers the innermost is held under tension by the outer layers. If one outer most layer is breached as in a traumatic bend of the septum, the inner most tension is lost and the septum remains deviated. Subsequent scarring and fibrosis ensure this deviation remains ${ }^{13}$. Usually, the junction of the bony and cartilaginous septum is the area of greatest deviation due to trauma.

Other possible causes include thumb sucking, nose picking and inheritance. ${ }^{14}$

Many proposed methods of nasal airway analysis exist, including Rhinomanometry, acoustic rhinometry, and nasal peak flow. ${ }^{2}$ The measurements derived from these methods are not always reproducible and do not consistently correlate with a patient's subjective complaint of nasal obstruction. In general, these types of studies are useful for research in nasal obstruction but provide little clinical value in the decisionmaking process regarding surgery or medical management.

Various deviated nasal septum classification:

Mladina Classification ${ }^{15}$ (1987):

Type 1: midline septum or Mild deviation

Type 2: Anterior vertical, C-Shaped

Type 3: Posterior vertical, C-Shaped

Type 4: S- shaped deviation

Type 5: Horizontal spur

Type 6: Horizontal spur with deep groove on the concave side

Type 7: Combination

Various other classifications were proposed, I shall mention few of them.

Classification of DNS:

1. C shaped

2. $\mathrm{S}$ shaped

3. Caudal Dislocation

4. Spur

5.Thick Septum (Reduplication)

Petermilling (1953) classification

1.Anterior dislocation of the septal cartilage

2.Simple deviation with or without spur

3.Spur or crest without deviation of septum

4.Sigmoid deviation in vertical or anterioposterior direction

Negus (1955) classification

1. Spur

2. Deviations

3. Combination

Negus defines spur as a spine which is chiefly made up of cartilage but found at the junction of the bone and cartilage and invariably bone enters into its formation.

Ballenger (1959) classification

1.Deviation with or without crusts, spur and without external deformity.

2. Deviation associated with external nasa deformities.

3. Isolated deformities.

Oscar and Becker (1957) classified DNS into

1. Developmental type

2. Truamatic 
Lateral type

Depressed type

Lateral frontal type

Cotte's classification:

1. Simple- mild deflection that does not obstruct.

2. Obstructed- severe deflection touching lateral wall but shrinking on vasoconstriction.

3.Impacted- Marked angulations of the septum with a spur in contact with the lateral wall even application of a vasoconstrictor.

Treatment optionsSimple deviations with mild deflection of the septum which does not cause obstruction do not require any treatment.More severe deviations with or without impaction on the lateral wall of the nose is managed by surgical treatment. ${ }^{16,17}$ The essential indication of septal surgery being skeletal septal obstruction (Bony and cartaginous).

In many patients with septal deviations, there is also some generalized mucosal pathology in the form of a perennial rhinitis and this will not be corrected by septal surgery.

Septal surgeries for correction of deviated nasal septum ${ }^{18}$

1. Sub mucous resection

2. Septoplasty

- Conventional

- Endoscopic

- Laser assisted

- Radio frequency assisted

- Extra-corporeal

- Powered endoscopic nasal septal surgery

\section{Patients And Methods}

During the period August 2012 to September 2014, 30 cases of nasal septal deviation diagnosed at OPD of Govt ENT hospital, Koti were studied. Each patient's clinical details were taken down in a proforma (Data type). From every patient detailed history pertaining to auto laryngological symptoms has been collected and he/she has been subjected to thorough clinical examination. The patients have been also investigated in terms of routine blood examination and radiology. Diagnostic nasal endoscopy was done in every case and the findings have been compared with those of radiology.

A total number of 100 cases have been examined endoscopically and CT scan findings were taken. 30 cases of various grades based on Mladina classification has been chosen for the present study. The criteria for selection of cases for the present study has been significant symptomatic nasal obstruction, as the study includes surgical management of deviated nasal septum. The deviations anterior and posterior to Cottles line has been taken as Anterior deviations andposterior deviations respectively on CT PNS films.

The endoscopic findings and CT scan findings have been compared and surgery planned accordingly. Associated nasal disease has also been recorded treated, and data subjected to statistical analysis

Age and sex:

\section{Results}

The male female ratio in the present study is $21: 9$. The age incidence showed that, most of the patients were in 2 nd to 4 th decade with minimum age being 17 years and maximum 42 years.

Table 1: Age Distribution

\begin{tabular}{|l|l|}
\hline AGE & NO.OF PATIENTS \\
\hline $11-20$ years & 9 \\
\hline $21-30$ years & 12 \\
\hline $31-40$ years & 7 \\
\hline $41-50$ years & 2 \\
\hline
\end{tabular}




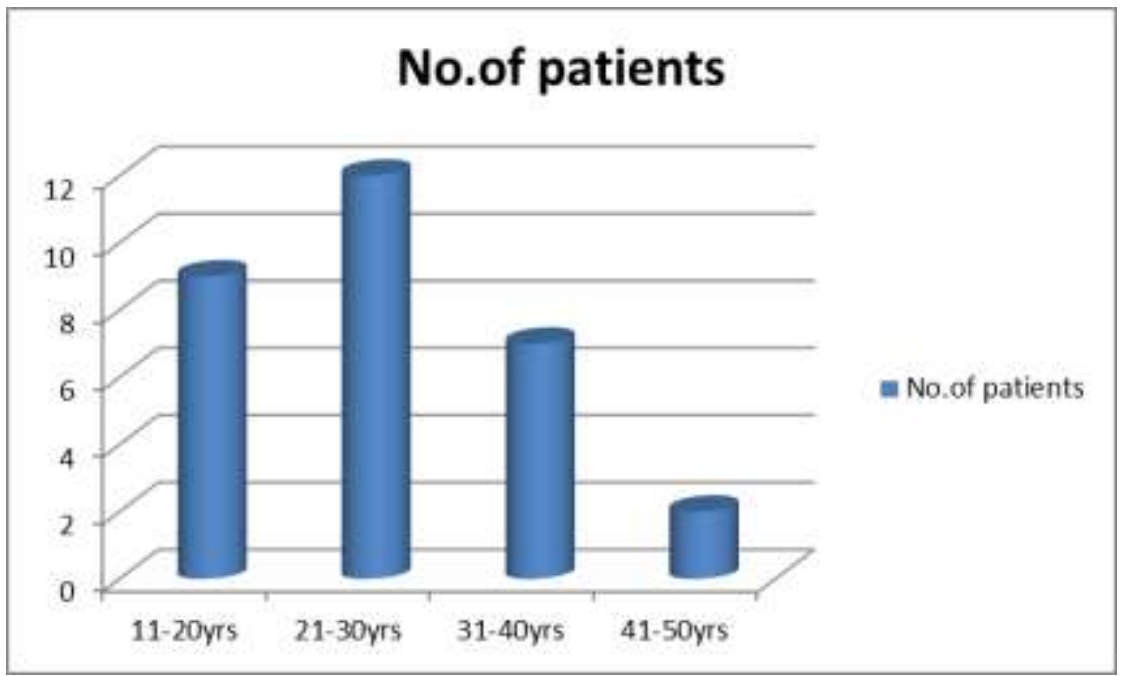

Fig.1 showing bar diagram of age distribution

Table 2: Sex Distribution

\begin{tabular}{|l|l|}
\hline Sex & No.of patients \\
\hline Male & 21 \\
\hline Female & 9 \\
\hline
\end{tabular}

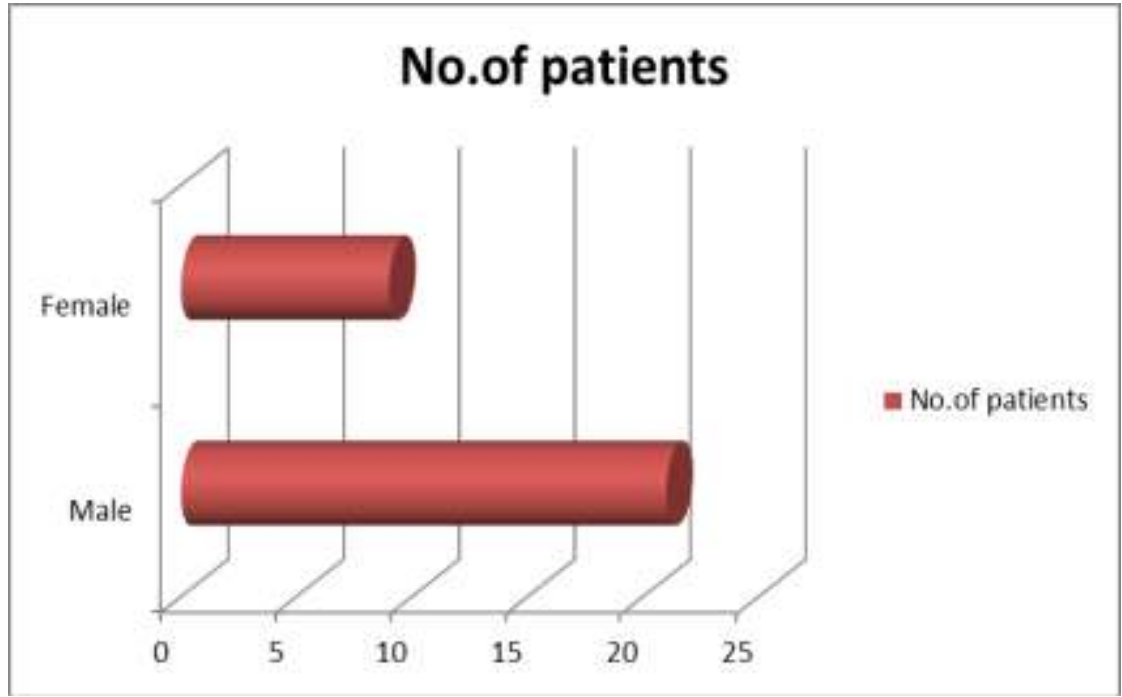

Fig 2 showing sex distribution

Table 3: Presenting Complaints

\begin{tabular}{|l|l|l|l|}
\hline S.No & PRESENTING COMPLAINTS & $\begin{array}{l}\text { No. of cases with } \\
\text { the complaint }\end{array}$ & Percentage \\
\hline 1. & Nasal Obstruction & 30 & 100 \\
\hline 2. & Nasal Discharge & 21 & 70 \\
\hline 3. & Headache & 26 & 86 \\
\hline 4. & Sneezing & 3 & 10 \\
\hline 5. & Throat Discomfort & 18 & 60 \\
\hline 6. & Post nasal Drip & 18 & 60 \\
\hline 7. & Nasal bleeding & 8 & 26 \\
\hline 8. & Snoring & 7 & 23 \\
\hline 9. & Anosmia & 4 & 13 \\
\hline 10. & Total no.of cases & 30 & -- \\
\hline
\end{tabular}




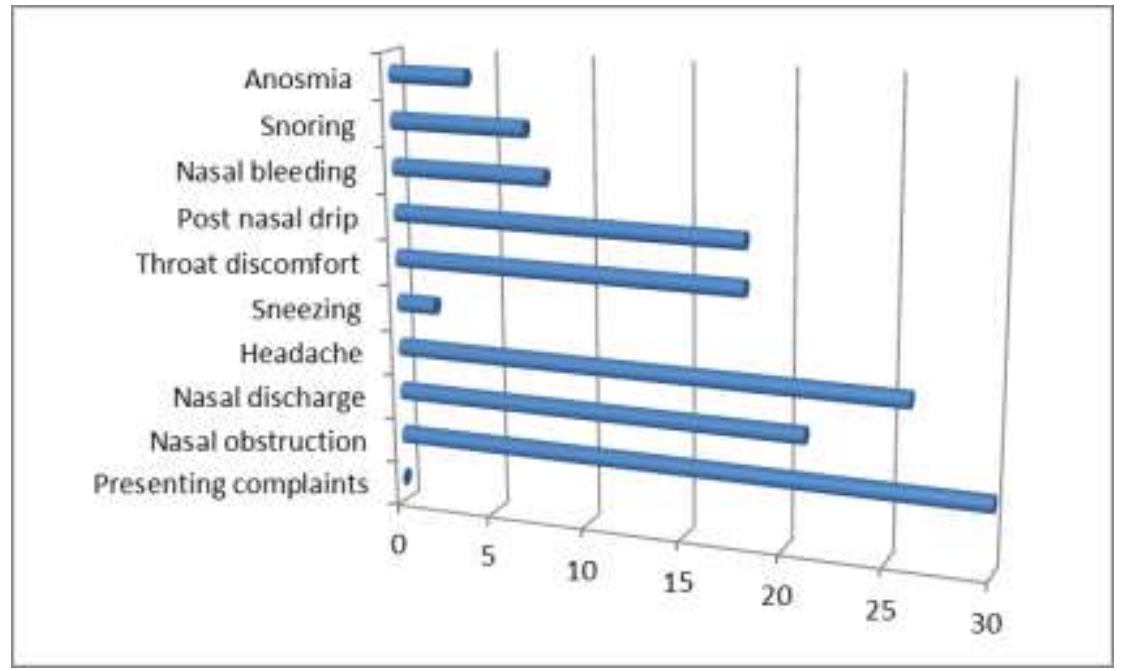

Fig 3 line diagram showing symptomatology of deviated nasal septum

The study of presenting complaints showed that 30 of 30 patients had nasal obstruction, while 21 had nasal discharge; Headache was the complaint in 26 patients. Nasal obstruction being predominant Symptom of the deviated nasal Septum cases. The other problems seen in a small number of patients were throat discomfort, epistaxis, snoring post nasal drip and Anosmia (Table-3).

\section{Type of deviation:}

The results of the types of deviated nasal septum reveals vertical deviation accounted for majority of cases.--Types 2, 3, 4. Type 1 is seen in only 1 case of this study, nasal obstruction in this 1 case probably attributable to allergic rhinitis. Type 3 nasal septal deviation constituted $26 \%$ of the cases.

Table 4 showing Type of deviation and percentages

\begin{tabular}{|l|l|l|l|}
\hline S.No & Type of Deviation & No.of Cases & Percentage \\
\hline 1 & $\begin{array}{l}\text { Midline septum or Mild } \\
\text { deviation }\end{array}$ & 1 & 3.3 \\
\hline 2 & Anterior vertical, C shaped & 7 & 23.33 \\
\hline 3 & Posterior vertical, C shaped & 8 & 26.66 \\
\hline 4 & S shaped deviation & 4 & 13.33 \\
\hline 5 & Horizontal spur spur with deep & 3 & 20 \\
\hline 6 & $\begin{array}{l}\text { Horizontal soove on the concave side } \\
\text { groovion }\end{array}$ & 1 & 12 \\
\hline 7 & Combination & 3.3 \\
\hline & Total & 30 & \\
\hline
\end{tabular}

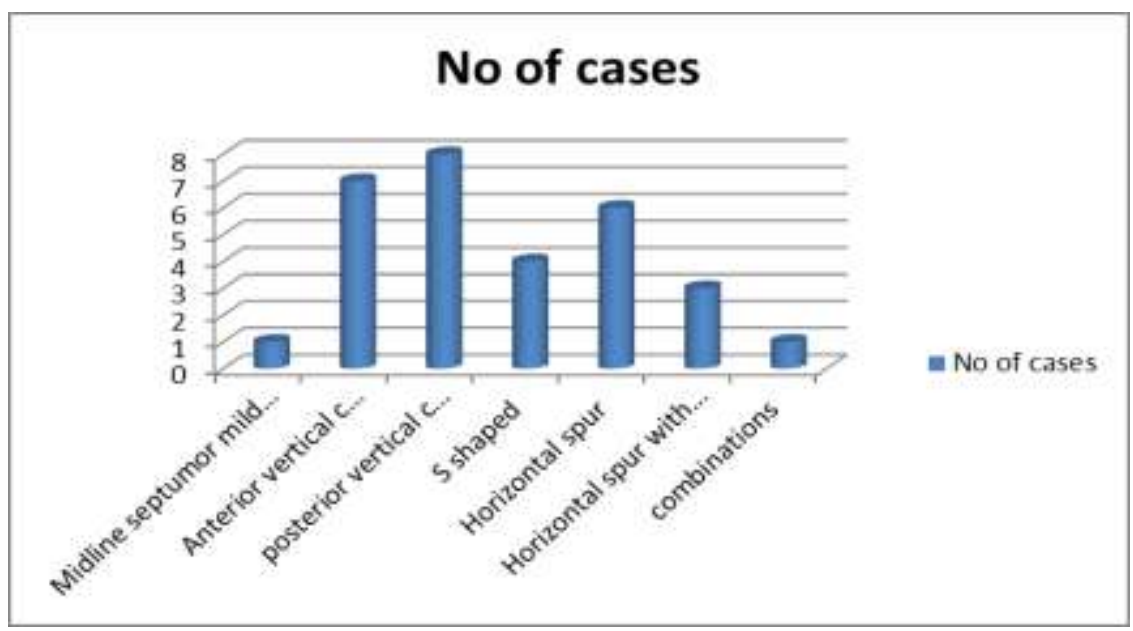

Fig 4 showing no of cases with types of deviation . 
Clinical and radiological evaluation of deviated nasal septum in classifying ...

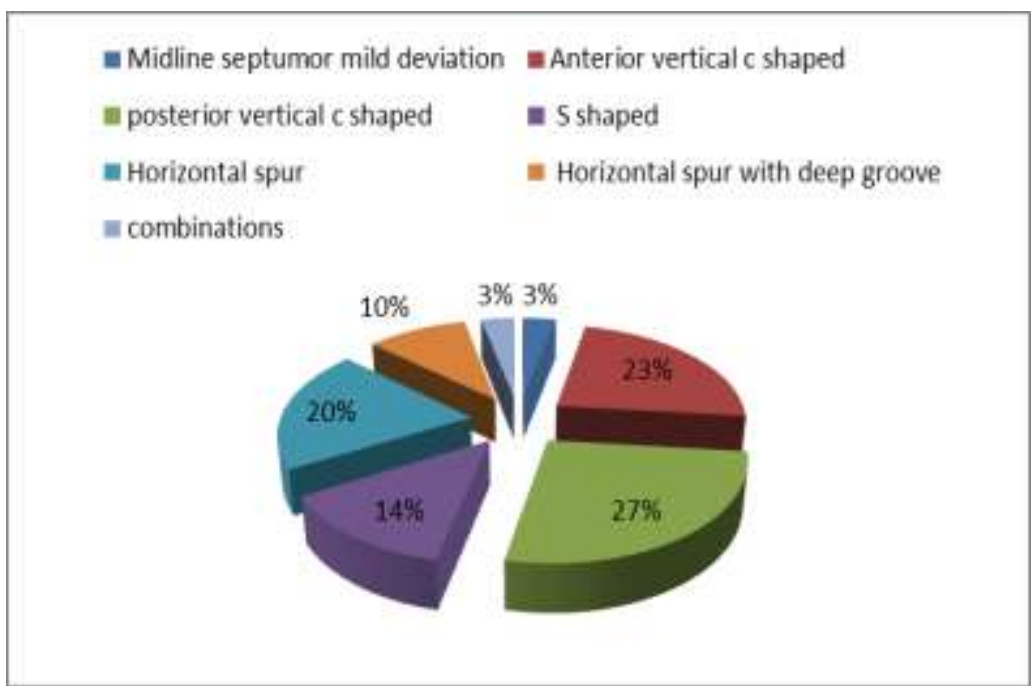

Fig 5: Types of deviation in percentages.

\section{Discussion}

Nasal septal deviation is a common condition of the patients who visit ENT surgeon. But till now, there was no universally accepted classification of deviated nasal septum; the classification is useful for assessment of the patient and to plan the treatment. It is also useful to explain the patient, the severity of the deviation and be realistic about the septal Surgery. The classification system also helps to plan septoplasty with other surgeries like FESS, to give better results. There were nospecific studies to answer the above issues adequately.

\section{Mladina ${ }^{19}(1987)$ classified the nasal septal deviations into 7 types Which Was later frontal typecottle's classification:}

1.simple - mild deflection that does not obstruct

2.Obstructed-severe deflection touching lateral wall but shrinking on vasoconstriction

3.Impacted - Marked angulations of the Septum with a spur in contact with the lateral wall even after the application of a Vasoconstrictor.

Mladina classification was the relevant and recent one and, he suggested that the classification should be followed and included in data of chronic rhino sinusitisso that final elucidation of real role and importance of septal deviations is clearer.

In this study it was found that type 3 and type 5 nasal septal deviations aremore common in patients with sinonasal disease and also anatomical variants arealso more common with type 3 .

The aim of present study is to analyze the clinical and C.T. PNS findings in symptomatic deviated nasal septal cases and attempt to classify the septal deviations into 7 types according to Mladina's classification .The Mladina's classification was used because, it is most recent and relevant to define the role of septal deviations in relation to severity of symptoms and to predict the Sino nasal deviation in DNS cases.

In this study $46 \%$ of patients were types 3 and 5 while $51 \%$ were types 2,4 , and 7 . Only 1 patient had type 1 Septum. Significant clinical severity of Symptomatology was noted in types $3 \& 5$ and minor degree of severity was noted in types. This suggests that type 5 and 3 have higher probability of developing complications of septal deviation.

Further studies on wider groups are indicated to confirm the association of type of deviated nasal septum and severity of septal deviation. Such studies are important because we can determine exactly the relation of the type of nasal septal deviation to the complication of septal deviation and it might be advisable to do prophylactic septoplasty in patients with early signs of nasal septal deviation complications like development of Sino nasal disease.

Septal deviation is one of the most common causes of nasal obstruction. The presence of posterior septal deviation can result in nasal obstruction, in addition to other presenting symptoms associated with it. Various techniques have been described for the correction of deviated septum (Cottle et al., 1958, \& Maran, $1974)^{20}$. Increased incidence of complications of septal surgery led to more and more conservative septoplasty which can be safely performed in children, without fear of possible poor development of the mid face. (Maran, 1974). For a good septoplasty, it is necessary to understand the pathological abnormalities operatively and the nasal endoscope has become a remarkable aid allowing closer vision of the abnormalities in remote areas and hence providing relative magnification. Because the endoscope can be passed easily under septal mucosal flaps, minimal retraction of the flaps is required to gain excellent visualization. As the incision can be performed more 
posteriorly in the nose, the extent of mucosal elevation anteriorly in the nose is minimized, hence postoperative edema is reduced. Furthermore, endoscopic evaluation of the nasal airway permits visualization without physical distortion of nasal anatomy.

Stammberger ${ }^{21}$ (1991), Lazer et all ${ }^{22}$ (1993), Giles et al ${ }^{23}$, (1994), Cantrell ${ }^{24}(1997)$, Nayak et al ${ }^{25},(1998)$ and Hwang et $\mathrm{al}^{26}$., (1999) have all described limited endoscopic septoplasty either alone or in conjunction with functional endoscopic sinus surgery (FESS) with variable indications in each series.

In the present study it is concluded that in cases of symptomatizing posterior septal deflection or spur with limited extent, limited endoscopic septoplasty is indicated. Pre operative nasal endoscopy and coronal CT scan is mandatory to detect the extent of septal deviation and any associated pathology.

\section{Conclusions}

A standard classification of nasal septal deviationshould be developed and followed so that it can be included in evaluating the symptomatology and severity of the deviated nasal septum.

The present study reveals:

- Mladina's classification is acceptable in evaluation of the deviated nasal septum patients.

- Type 3 (posterior) and type 5 (horizontal spur) are the types of septal deviations associated with more severity and complications of deviated nasal septum

- Evaluation of deviated nasal septum endoscopically and comparison with CT scan helped in planning for surgery and optimizing the results

- Evaluation of deviated nasal septum endoscopically and comparisonwith CT scan helped in optimizing the results of septoplasty and co-existing morbidity.

The advantages of the nasal endoscope in the management of limited posterior septal deviation include the following:

-It facilitates accurate identification of the pathology due to better illumination and improved accessibility to remote areas.

-It helps better understanding of the lateral wal pathology associated with septal deformity.

-It allows limited incision and elevation of the flaps that are not compromised with adequate exposure of the pathological site and this will minimize the extend of postoperative oedema.

-Elevation of the flap in the correct plane will also minimize the Intraoperative bleeding.

- Effectively relieves the contact areas and thus the contact headache by allowing accurate intra operative assessment.

- Effective for teaching students.

- Ultraconservative techniques, with the landmarks well preserved, it keeps the option open for revision surgery, if indicated.

The limitation of this procedure includes

-Loss of binocular vision

- Takes longer time

- Expertise and training is needed

Thorough evaluation of deviated nasal septum by endoscopy and comparison with CT scan of paranasal sinuses and adhering to a standard classification of deviated septumsprovesto be excellent protocol to achieve accurate diagnosis and significantly successful surgicaloutcome.

\section{References}

[1]. Renner G J. Management of nasal fractures. OtolaryngolClin North Am. 1991;24:195-213.

[2]. Evaluation and Reduction of Nasal Trauma, Brian P. Kelley, B.S.,1 Cara R. Downey, M.D.,1 and Samuel Stal, M.D.SeminPlast Surg. 2010 Nov; 24(4): 339-347

[3]. Murray J A, Maran A G. The treatment of nasal injuries by manipulation. J Laryngol Otol. 1980;94:1405-1410.

[4]. Daniel G. Becker, MD, Septoplasty and Turen Surgery, Aesthetic surgery ournal September 1 October 203393.

[5]. Vainio-Mattila J. Correlations of nasal symptoms and signs in random sampling study. ActaOtolaryngal suppl. 1974;318:1-48.

[6]. Takahashi R: The formation of nasal septum deformation in human evolution. Rhinology 1977, 15: 12-20.

[7]. Rudert H., Fromkillian'ssubmucous septum resection and Cottle's septoplasty to modern plastic septum correction and functional septorhinoplasty, HNO. 1984 Jun;32(6):230-3

[8]. Alpini D, Corti A, Bursa E, Bini A: Septal deformation in newborn infants. Int J PediatrOtorhinolaryngol 1986, 11: 103-107.

[9]. Korantzis A, Cardamakis E, Cheliodonis E, Papamihalis T: Nasal septum deformity in the newborn infant during labour. Eur J ObstetGynecolReprodBiol 1992, 44: 41-46.

[10]. Grymer LP, Pallisgaard C, Melsen B: The nasal septum in relation to the development of the nasomaxillary complex: A study in identical twins. Laryngoscope 1991, 101: 863-868.

[11]. Quante M, Franzen G, Strauss P: The correlation between permanent septal deformities and nasal trauma during birth. Rhinology 1976, 16: 141-146.

[12]. Grey LP: Prevention and treatment of septal deformity in infancy and childhood. Rhinology 1977, 15: 183-191. 
[13]. Hatef D A, Cole P D, Hollier L H., Jr Contemporary management of pediatric facial trauma. CurrOpinOtolaryngol Head Neck Surg. 2009;17:308-314.

[14]. Deformation of the nasal septum in children, adolescents, and adults in Western Pomerania Province of Poland I TeulEmail author, W Zbislawski, S Baran and F Czerwinski .European Journal of Medical Research200914(Suppl 4):244

[15]. Mladina R, Bastaic L: What do we know about septal deformities? J Rhinol 1997, 2: 79-89

[16]. Hwang, P.H., Mclaughlin, R.B., Lanza, D.C. and Kennedy, D.W. (1999): Endoscopicseptolasty: indications, technique, and results. Otolaryngol. Head \& Neck Surg, 120: 678-82.

[17]. CantreII, H (1997). Limited septoplasty for endoscopic sinus surgery. Otolaryngol Head \& Neck Surgery, 116: 274-277.

[18]. Stammberger, H. (1991): Functional Endoscopic Sinus Surgery BC. Decker Philadelphia, 156-159,430-434.

[19]. Mladina R, Cujic E, Subaric M, Vukovic K: Nasal septal deformities in ear, nose, and throat patients: an international study. Am J Otolaryngol 2008, 29: 75-82.

[20]. Cottle MH, Loring RM, Fischer GG, Ganyon IE et al (1958) The maxilla-premaxilla approach to extensive nasal septum surgery. AMA Arch Otolaryngol 68:301-313.

[21]. Stammberger H (1991) Functional endoscopic sinosurgery. B.C. Decker, Philadelphia pp 156-159, 430-434

[22]. Lazar, R.H. Youns, R.T. and Long, T.E. (1993). Functional endoscopic sinus surgery in adults and children. Laryngoscope, 103:1-5.

[23]. Giles W.C, Gross, C.W, Abroam A. C, (1994): Endoscopic septoplasty. Laryngoscope 104:1507-9.

[24]. CantreII, H (1997). Limited septoplasty for endoscopic sinus surgery. Otolaryngol Head \& Neck Surgery, 116: 274-277

[25]. Nayak, D.R., Balakrishnan, Rand Murthy, KD (1998): An endoscopic approach to the deviated nasal septum - a preliminary study. Journal of laryngology and Otology, 112: 934-939.

[26]. Hwang, P.H., Mclaughlin, R.B., Lanza, D.C. and Kennedy, D.W. (1999): Endoscopicseptolasty: indications, technique, and results. Otolaryngol. Head \& Neck Surg, 120: 678-82. 